\title{
Characterization of Weld Metal Microstructure in a Ni-30Cr Alloy with Additions of Niobium and Molybdenum
}

Rebecca A. Wheeling and John C. Lippold

Welding Engineering program

The Ohio State University

\begin{abstract}
Additions of niobium ( $\mathrm{Nb}$ ) and molybdenum (Mo) were made to an Alloy 690 base alloy in order to investigate the formation of a eutectic constituent at the end of solidification and to evaluate the effect of the eutectic liquid on backfilling (or healing) of solidification cracks. Solidification cracking was induced using the cast pin tear test (CPTT) and regions of backfilling were located and characterized via optical and electron microscopy. Computational predictions of fraction eutectic and composition of the eutectic constituent were compared to experimental findings and were found to correlate well in both cases. The extent of crack backfilling increased significantly with increasing $\mathrm{Nb}$ content, but the addition of Mo did not seem to influence the amount of eutectic constituent or the degree of backfilling. SEM/EDS analysis confirmed that the eutectic composition is constant and that increasing $\mathrm{Nb}$ above $4 \mathrm{wt} \%$ has little effect on expanding the solidification temperature range, but has a beneficial effect on mitigating solidification cracking by a crack healing effect.
\end{abstract}

\section{Introduction}

Nickel-based alloys with nominally 30 weight percent chromium are popular in high temperature applications which require general corrosion and stress corrosion cracking resistance, particularly for nuclear power and petrochemical applications [1]. With its superior resistance to stress corrosion cracking, Ni-base Alloy 690 has largely replaced Alloy 600 in many nuclear applications. With regards to 
the filler metals designed for use with this alloy, solidification cracking during welding remains a significant risk, especially with the use of consumables that are alloyed with $\mathrm{Nb}$ to eliminate ductility dip cracking (DDC). Nb plays an important role in reducing susceptibility to DDC by promoting the formation of $\mathrm{NbC}$ at the end of solidification via a eutectic reaction. These carbides are effective at pinning the crystallographic, "migrated' grain boundaries that form at the end of solidification, creating a “tortuous" grain boundary path which provides resistance to DDC [2, 3, 4, 5, 6, 7].

However, $\mathrm{Nb}$ can result in increased susceptibility to solidification cracking as segregation of $\mathrm{Nb}$ promotes a terminal eutectic reaction and an expansion of the solidification temperature range $[7,8,9,10$, 11, 12]. High fractions of eutectic constituent that form at the end of solidification have been associated with "crack healing" that occurs when cracks are "backfilled" by the eutectic liquid if the amount present is sufficient $[7,13,14,15]$. Figure 1 illustrates the effect of crack healing on cracking susceptibility in Alloy 690 with $\mathrm{Nb}$ additions. Note that the addition of up to 4 wt. \% $\mathrm{Nb}$ increases cracking susceptibility, but above this level, a decrease occurs, likely due to backfilling. This study investigates the amount and composition of the eutectic phase in Alloy 690 as a function of $\mathrm{Nb}$ and Mo additions.

The objectives of this study were to 1) evaluate the effect of $\mathrm{Nb}$ and Mo on the formation of liquid of eutectic composition at the end of solidification and 2) determine the relationship among composition, fraction eutectic and degree of crack healing. A fundamental understanding of this interrelationship will allow filler metals to be selected or compositionally modified to prevent solidification cracking via a backfilling mechanism. This is particularly important in austenitic (fcc) systems such as Ni-base alloys and austenitic stainless steels where solidification cracking can be a problem.

\section{Materials and Methods}


Computational and experimental methods were employed in this study to predict and compare the amount and composition of eutectic constituents as a function of additions of niobium and molybdenum to Alloy 690.

Solidification Simulation. The Scheil module within ThermoCalc ${ }^{\mathrm{TM}}$ provides a method to predict solute redistribution using a "non-equilibrium lever rule" in multicomponent systems. It assumes microscopic solidification and thus can account for microsegregation of elements to solidification subgrain and grain boundaries [16]. Three key assumptions are made during Scheil analysis: 1) no diffusion occurs in the solid phases once they are formed, 2) infinitely fast diffusion occurs in the liquid and 3) equilibrium exists at the solid-liquid interface [16]. The simulation occurs in a stepwise manner during cooling from above the liquidus until the lowest temperature where liquid can exist is reached. After each new step (temperature decrease), the new liquid composition becomes the "local overall" composition for the next step [16].

Thermocalc ${ }^{\mathrm{TM}}$ software was utilized to predict both the mass fraction of eutectic constituents as well as the average composition of the backfill region, as a function of the change in $\mathrm{Nb}$ and Mo additions. In this case, weight fraction values are comparable to volume fraction values due to the nearly equivalent close density of phases [17].

Sample Preparation. Samples of varying composition with respect to $\mathrm{Nb}$ and Mo were produced using a button melting technique. $\mathrm{Nb}$ additions ranging from 2 to $8 \mathrm{wt} \%$ were made to the Alloy 690 base alloy. Additions of 2 and $4 \mathrm{wt} \%$ Mo were made to alloys containing 4 and $6 \mathrm{wt} \% \mathrm{Nb}$. Including the base alloy, a total of 11 compositions were evaluated. These compositions were tested for solidification cracking susceptibility using the Cast Pin Tear Test (CPTT). Details of the CPTT have been described elsewhere $[18,19]$ Cast pins that were below the cracking threshold (longest pins that exhibits no surface cracking) were then sectioned and characterized.

Characterization. Pins were sectioned axially or longitudinally to reveal microstructures from the pin center and close to the pin exterior, respectively. All samples were mechanically polished and 
electrolytically etched in chromic acid for 5-10 seconds at 5 volts and 2 amps with a tungsten anode and stainless steel cathode. The microstructure of each sample set was characterized using both optical (Olympus GX51) and scanning electron (Quanta 200 and Sirion) microscopes. Volume fraction eutectic was determined via image analysis performed using ImageJ software. The procedure was developed from work by Payton et. al. and conformed to ASTM E1245-03 [20,21]. An example is shown in Figure 2. The eutectic composition was also analyzed in the SEM with energy dispersive spectroscopy (EDS) in order to determine the composition of regions exhibiting crack backfilling by the Nb-rich eutectic phase.

\section{Results and Discussion}

ThermoCalc ${ }^{\mathrm{TM}}$ Simulations. Results of the Scheil simulations for all the alloy compositions are provided in Table 1. This table also contains results of the optical metallography evaluation using image analysis. Both mass and volume fraction predictions correlated to the volume fraction measured metallographically, although the calculated volume fractions were slightly higher than the calculated mass fraction values. The average weight fraction of $\mathrm{Nb}$ and $\mathrm{Mo}$ in the final eutectic region both were predicted to increase as addition of both elements increased. The predicted $\mathrm{Nb}$ concentration of the terminal eutectic constituent increases only slightly from $\sim 20$ to $\sim 23 \mathrm{wt} \%$ as the $\mathrm{Nb}$ addition is increased from 2 to $8 \mathrm{wt} \%$. This is consistent with the fact that the eutectic composition is essentially fixed in terms of $\mathrm{Nb}$ content and, while partitioning appears to increase slightly with increasing $\mathrm{Nb}$ content, the effect is not extreme. In contrast, Mo partitioning correlates closely with increased Mo content. As Mo doubles from 2 to $4 \mathrm{wt} \%$, the calculated Mo fraction in the eutectic region also doubles, indicating that segregation of Mo appears to be a direct function of the amount added.

Image Analysis. The fraction eutectic was experimentally determined for all the compositions with only $\mathrm{Nb}$ additions (Table 1). Metallographic analysis showed that the addition of Mo had no apparent effect on fraction eutectic. Figure 1 shows the progression of the image analysis process that was used for each 
optical micrograph. All the values shown represent the percentage of eutectic constituent (dark etching) present in the sample. For each composition, 7-10 micrographs from different samples and locations were analyzed in order to determine a statistically significant average of the volume fraction eutectic. Table 2 provides the image analysis results for all compositions in which fraction eutectic was measured.

As expected, the measured volume percent eutectic increases as the $\mathrm{Nb}$ addition increases. The $95 \%$ confidence interval (CI) and percent relative accuracy (RA) values determine the statistical significance of the measured data. The ASTM standard for measuring fractions of inclusion explains these values in detail [21]. The 95\% CI values predict where additional measurements should fall relative to the average vol. \% eutectic calculated from the collected data set (each composition). None of the $95 \%$ CI values predict intersections between any of the data sets, so precision in the data is apparent. While not entirely practical within experimental timeframes, the \% RA estimates the percent of error among measurements as influenced by a field-to-field variability of the mean and standard deviation for a given number of fields. Values of \% RA less than 30 generally indicate small differences between samples, as is the case when the fraction eutectic is high $(4,6$ and $8 \mathrm{wt} \% \mathrm{Nb}$ additions). At low fraction eutectic levels, it is very difficult to obtain such low \% RA values when dealing with low volume fractions of inclusions without 200-300 fields (samples). Since these values were calculated from only 7-10 samples, the \% RA values may appear high in the lower alloy additions but generally exhibit low field-to-field variability. This indicates that changing the location of analysis might have a small effect on the fraction eutectic, but not so large as to cause the data to be unrepresentative. While the image analysis was meticulously carried out, the self-filling step is a source for human error. Unless this step is carried out consistently, the fraction eutectic values are likely to vary. The image analysis, in this case, appears to produce statistically reliable data. Figure 3 compares the computed fraction eutectic values with the measured values. 
The predicted values predict a similar increasing trend suggesting that ThermoCalc ${ }^{\mathrm{TM}}$ is a good tool for calculating fraction eutectic in these Ni-based alloys. Quantitative image analysis was not performed on samples containing molybdenum, but a qualitative comparison of the microstructure shown in Figure 3 indicates that the fraction eutectic values were not dramatically changed by the addition of molybdenum which is supported by Thermocalc ${ }^{\mathrm{TM}}$ predictions.

While it is possible that the molybdenum additions may slightly affect the fraction eutectic, Figure 4 suggests that additions of up to $4 \mathrm{wt} \%$ Mo have little influence and that the dominant effect comes from the addition of $\mathrm{Nb}$. As will be discussed in the next section, Mo additions appear to have a large influence on the eutectic composition while only a small influence on volume fraction.

Backfilling of Cracks. Regions of backfilling in the cast pins were characterized with optical and scanning electron microscopy. Pins selected for the backfilling studies were those that were below the cracking threshold in the CPTT and did not exhibit any apparent cracking on the pin surface. Figures 5-7 show backfilled cracks in four different sample compositions [22].

The backfilled regions shown in Figure 5 are sparse and often unconnected in the $2 \mathrm{Nb}$ samples, probably due to the lower fraction eutectic present in this alloy. The $6 \mathrm{Nb}$ samples produce a more extensive and continuous network. It is difficult to discern an effect of the Mo additions at either Nb level, although at the $6 \mathrm{Nb}$ the backfilled cracks appear to be wider. This may have more to do with the nature of the actual crack that was backfilled rather than a real $\mathrm{Nb}$ effect. Similar to the solidification data in Table 1, it is 
difficult to determine the effect of Mo, even though CPTT results showed that some reduction in cracking occurs when Mo is added to the $6 \mathrm{Nb}$ alloys.

Figures 6 and 7 show the clear difference in the effect of fraction eutectic on backfilling when comparing low and high $\mathrm{Nb}$ alloys. All micrographs are from pins at the critical cracking threshold (pin length just below where surface cracks are abserved). The $2 \mathrm{Nb}$ sample in Figure 6 shows a completely healed crack along a solidification grain boundary, even though the fraction eutectic is relatively low. The $8 \mathrm{Nb} 0 \mathrm{Mo}$ sample in Figure 7 has extensive backfilling that has almost completely healed a crack that formed in the cast pin test. Only a small amount of open crack exists near the pin surface. The effect of $\mathrm{Nb}$ clearly has a dominant effect on the formation of eutectic liquid and hence the degree of backfilling.

Figure 8 shows results of EDS spot scans for $\mathrm{Nb}$ additions (top) and NbMo additions (bottom).

When comparing the measured composition values shown in Figure 8 to the calculated values from Table 1 , it is important to note that the calculated values represent an average composition. Depending on the size and location of the spot analyzed using SEM/EDS, the value may not approximate the average composition that is calculated. It was determined that at the very center of the backfilled regions, the eutectic lamellae spacing was less than $1 \mu \mathrm{m}$, so spots placed in this area likely correspond to an average composition. However, the spacing increases closer to the edge of the eutectic so in samples with very narrow backfilled regions, the SEM/EDS analysis is less likely to represent an average value. With respect to niobium in the backfilled regions, the $4 \mathrm{Nb} 0 \mathrm{Mo}, 6 \mathrm{Nb} 2 \mathrm{Mo}, 6 \mathrm{Nb} 4 \mathrm{Mo}$, and $8 \mathrm{Nb} 0 \mathrm{Mo}$ samples exhibited $\mathrm{Nb}$ concentrations similar to those predicted by ThermoCalc ${ }^{\mathrm{TM}}$ in Table 1 . The Nb-enriched areas in the $2 \mathrm{Nb} 2 \mathrm{Mo}$ and $2 \mathrm{Nb} 4 \mathrm{Mo}$ samples appear significantly lower in niobium than the predicted values. As noted above, the reported values may not accurately represent an average value. It is clear that the $\mathrm{Nb}$ concentrations measured in the $6 \mathrm{Nb} 0 \mathrm{Mo}$ sample are not representative of an average value, as 
values that are significantly higher and lower than the predicted value are reported. In terms of Mo, measured values are below the enrichment level predicted. More detailed analysis using higher resolution electron microscopy (TEM) may provide more information on the nature and amount of Mo segregation.

\section{Conclusions}

1. Increasing fraction eutectic as a function of $\mathrm{Nb}$ content, as predicted by ThermoCalc ${ }^{\mathrm{TM}}$, is consistent with values determined from optical metallography and image analysis.

2. Niobium additions had the most significant effect on the fraction eutectic formed at the end of solidification. Molybdenum additions had little effect on fraction eutectic but did influence the composition of the eutectic constituent as measured using SEM/EDS. Thermocalc ${ }^{\mathrm{TM}}$ overestimates the Mo content in the final eutectic.

3. Increased levels of niobium resulted in a higher degree of crack backfilling and leads to a lower cracking susceptibility.

4. The beneficial effect of molybdenum relative to cracking resistance is not associated with the fraction eutectic formed but may influence the nature of the eutectic liquid along the solidification grain boundary.

\section{Acknowledgements}

Thanks are acknowledged to The Ohio State University for providing a University Graduate Fellowship to support the primary author during the period this investigation was conducted. The Department of Energy Integrated University Program (IUP) is also recognized for providing continued funding for this project. The assistance and advice of fellow graduate students Adam Hope, David Tung, and Daniel Tung is greatly appreciated. Helpful insight from Paul Mason at ThermoCalc ${ }^{\mathrm{TM}}$ is also recognized. Finally, 
thanks to Ken Copley and Ed Pfeiffer from the Welding Engineering Program for their dedication to maintaining a safe and stimulating laboratory environment.

\section{References}

[1] "Inconel Alloy 690," 2009.

[2] A. Ramirez, J. Sowards and J. Lippold, "Improving the Ductility-Dip Cracking Resistance of Ni-base Alloys," Journal of Materials Processing Technology, vol. 179, pp. 212-218, 2006.

[3] S. McCraken, "Dissimilar Metal WEld Issues and Repair Strategies in the Nuclear Industry," Electric Power Research Institute, 2015.

[4] S. Kiser, R. Zhang and B. Baker, "A New Welding Material for Improved Resistance to Ductility Dip Cracking," Special Metals Welding Products Company and Huntington Alloys/Special Metal Corporation, 2008.

[5] J. C. Lippold, S. D. Kiser and J. N. DuPont, Welding Metallurgy and Weldability of Nickel Base Alloys, Noboken, N.J.: Jouhn Wiley \& Sons, 2009.

[6] S. Kazuyoshi, K. Bunda, H. Ogiwara and K. Nishimoto, "Hot Cracing Susceptibility of Commercial Alloy 52 Filler Metals in Multipass Welding of Alloy 690," in Trends in Welding Research, Proceedings of the 9th International Conference, 2012.

[7] T. Bollinger, H. Herald, C. Cross and J. Lippold, Eds., in Hot Cracking in Welds II, Springer, 2008, pp. 166, 169, 208.

[8] A. Ramirez, J. Sowards and J. Lippold, "Improving the Ductility-Dip Cracking Resistance of NiBase Alloys," Journal of Materials Processing Technology, vol. 179, pp. 212-218, 2006.

[9] S. McCracken, "Dissimilar Metal Weld Issues and Repair Strategies in the Nuclear Industry," in Electric Power Research Institute, 2015. 
[10] S. Kiser, R. Zhang and B. Baker, "A New Welding Material for Improved Resistance to Ductility Dip Cracking," NC and WV, USA.

[11] J. C. Lippold, JOHNS BOOK> COME BACK.

[12] S. Kazuyoshi, K. Bunda, H. Ogiwara and K. Nishimoto, "Hot Cracking Susceptibility of Commercial Alloy 52 Filler Metals in Multipass Welding of Alloy 690," in Proceedings of the 9th International Conference, 2012.

[13] C. Huang, G. Cao and S. Kou, "Liquation Cracking in Partial Penetration Aluminum Welds: Assessing Tendencies to Liquate, Crack, adn Backfill," Science of Welding and Joining, vol. 9, no. 2, pp. 149-157, 01 April 2004.

[14] O. Idowu, O. Ojo and M. Chaturvedi, "Effect of Heat Input on Heat Affected Zone Cracking in Laser Welded ATI Allvac 718Plus Superalloy," Materials Science and Engineering A, pp. 389-387, 2007.

[15] M. Cieslak and W. Savage, "Weldability and Solidification Phenomena of Cast Stainless Steel," The Welding Journal: Welding Research Supplement, 1980.

[16] "Scheil Module," in Thermo-Calc for Windows Version 5 User's Guide, 2008.

[17] J. DuPont, "Solidification of an Alloy 625 Overlay," Metallurgical and Materials Transactions A, vol. 27A, pp. 3612-3620, 1996.

[18] V. V. C. Kreuter, "Optimization and Application of the Strain to Fracture Test," The Ohio State University, Columbus, 2015.

[19] B. Alexandrov and J. Lippold, "Use of the Cast Pin Tear Test to Study Solidification Cracking," Weld World, vol. 57, pp. 635-648, 2013.

[20] E. Payton, P. Phillips and M. Mills, "Semi-Automated Characterization of the Gamma' Phase in NiBased Superalloys via High-Resolution Backscatter Imaging," Materials Science and Engineering A, vol. 527, pp. 2684-2692, 2010.

[21] ASTM International Designation: E1245-03, 2008, pp. 909-916. 
[22] R. A. Wheeling and J. C. Lippold, "Solidification Cracking Susceptibility of Ni-30Cr Weld Metals with Variable Niobium, Molybdenum" The Welding Journal, Submitted 2015. 
Table 1. Compositions produced and corresponding mass and volume fractions eutectic $\left(f_{E}\right)$ predictions, measured volume fraction eutectic, and predicted weight fractions of niobium and molybdenum.

\begin{tabular}{|c|c|c|c|c|c|c|c|}
\hline Composition & $\mathbf{k}_{\mathbf{N b}}$ & $\mathbf{k}_{\mathbf{M o}}$ & $\begin{array}{c}\text { Calculated } \\
\mathbf{F}_{\mathbf{E}}\left(\mathbf{f}_{\mathbf{s}}=\mathbf{0 . 9 5}\right)\end{array}$ & $\begin{array}{c}\text { Calculated } \\
\mathbf{F}_{\mathbf{E}}\left(\mathbf{f}_{\mathbf{s}}=\mathbf{0 . 9 8}\right)\end{array}$ & $\begin{array}{c}\text { Measured } \\
\mathbf{V o l . ~}_{\mathbf{E}}\end{array}$ & $\begin{array}{c}\text { Avg. Final } \\
\text { Wt. } \\
\text { Fraction } \\
\mathbf{N b}\end{array}$ & $\begin{array}{c}\text { Avg. Final } \\
\text { Wt. } \\
\text { Fraction } \\
\text { Mo }\end{array}$ \\
\hline Alloy 690 & 0.16 & --- & --- & --- & $0.003 \pm 0.001$ & --- & --- \\
\hline 2Nb0Mo & 0.17 & --- & 0.00448 & 0.025522 & $0.014 \pm 0.006$ & 0.201 & --- \\
\hline 2Nb2Mo & 0.17 & 0.66 & 0.00319 & 0.026811 & --- & 0.191 & 0.0656 \\
\hline 2Nb4Mo & 0.17 & 0.68 & 0.00129 & 0.028708 & --- & 0.183 & 0.118 \\
\hline 4Nb0Mo & 0.18 & --- & 0.065893 & 0.095893 & $0.075 \pm 0.01$ & 0.217 & --- \\
\hline 4Nb2Mo & 0.18 & 0.67 & 0.068589 & 0.098589 & --- & 0.206 & 0.0700 \\
\hline 4Nb4Mo & 0.18 & 0.69 & 0.072664 & 0.102664 & --- & 0.199 & 0.124 \\
\hline 6Nb0Mo & 0.19 & --- & 0.15167 & 0.18167 & $0.144 \pm 0.03$ & 0.223 & --- \\
\hline 6Nb2Mo & 0.19 & 0.68 & 0.156274 & 0.186274 & --- & 0.212 & 0.0736 \\
\hline 6Nb4Mo & 0.19 & 0.69 & 0.160404 & 0.190404 & --- & 0.204 & 0.129 \\
\hline 8Nb0Mo & 0.20 & --- & 0.25281 & 0.28281 & $0.239 \pm 0.018$ & 0.227 & --- \\
\hline
\end{tabular}

Table 2. Average measured fraction eutectic values using image analysis, corresponding $95 \%$ confidence interval (CI), and percent relative accuracy (RA) for alloys with $\mathrm{Nb}$ added.

\begin{tabular}{|c|c|c|c|}
\hline Wt. \% Nb added & $\begin{array}{c}\text { Measured Vol \% } \\
\text { Eutectic }\end{array}$ & 95\% CI & \% RA \\
\hline 0 & $0.3 \pm 0.1$ & 0.12 & 41.38 \\
\hline 2 & $1.4 \pm 0.6$ & 0.55 & 39.64 \\
\hline 4 & $7.5 \pm 1.5$ & 1.01 & 13.44 \\
\hline 6 & $14.4 \pm 3.2$ & 3.36 & 23.32 \\
\hline 8 & $23.9 \pm 1.8$ & 2.23 & 9.35 \\
\hline
\end{tabular}




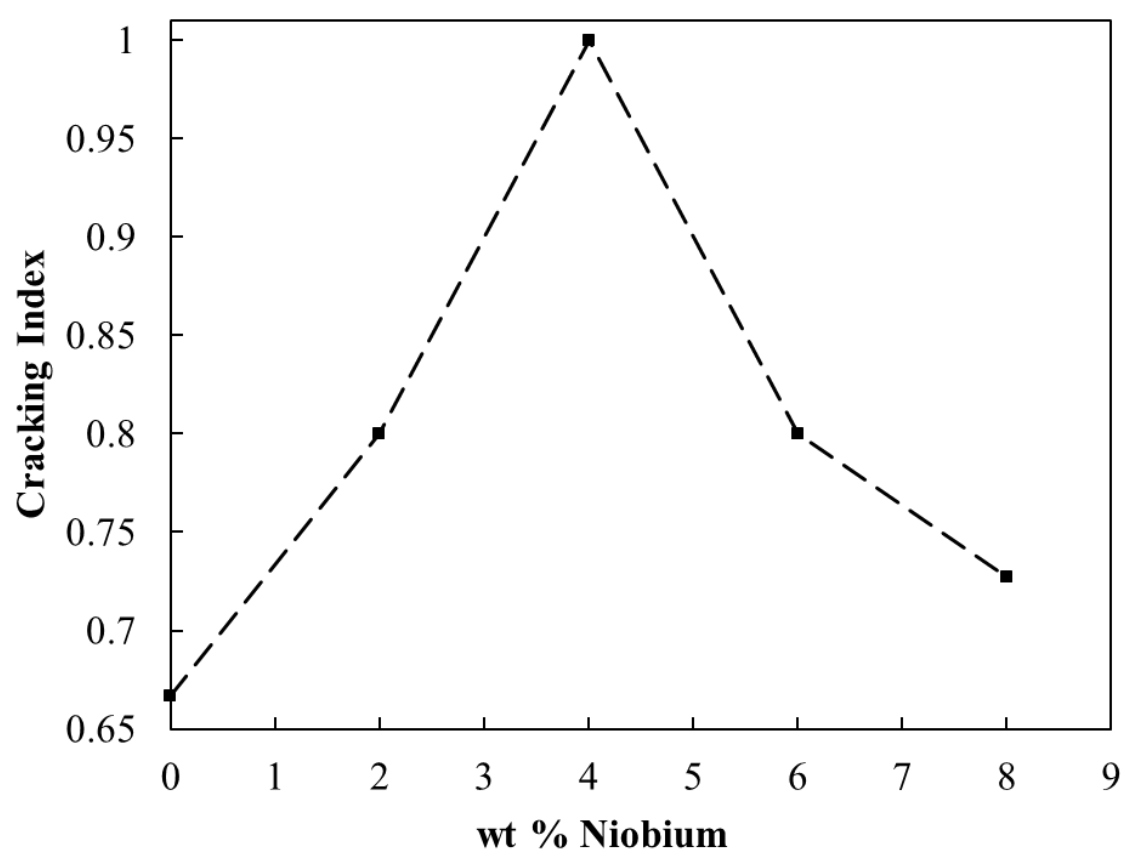

Figure 1. Solidification cracking susceptibility determined using the cast pin tear testing in Alloy 690 over a range of $\mathrm{Nb}$ additions.

a.) $6 \mathrm{Nb} 0 \mathrm{Mo}$ Pin

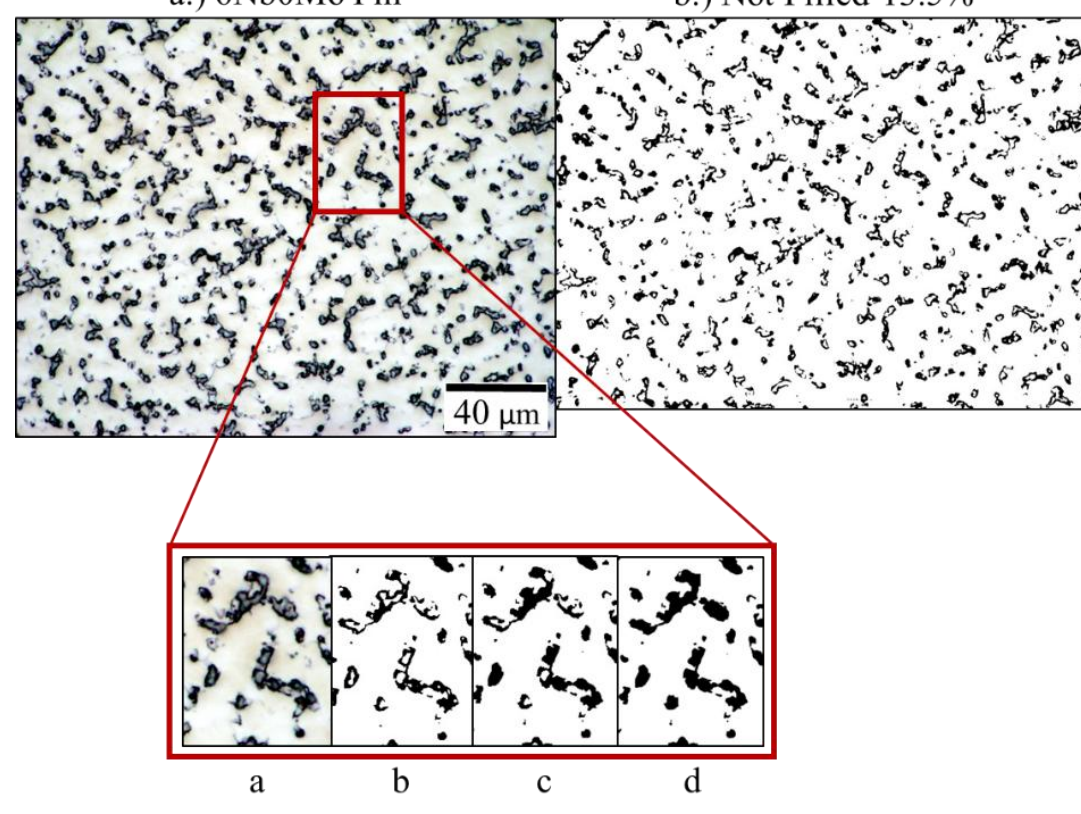

c.) Auto Filled-14.4\%

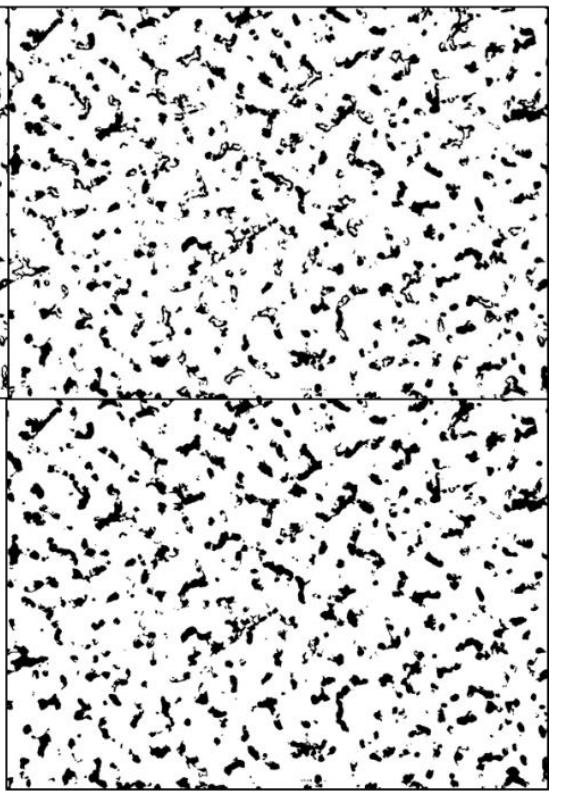

d.) Self-Filled-15.8\%

Figure 2. Progression of image analysis steps used to measure fraction eutectic of a $6 \mathrm{Nb} 0 \mathrm{Mo}$ sample in which the original optical micrograph (a) was converted to a binary image (b), automatic hole filling was performed (c), and the remaining holes were hand-filled (d) before the percentage of black pixels was determined [20]. 


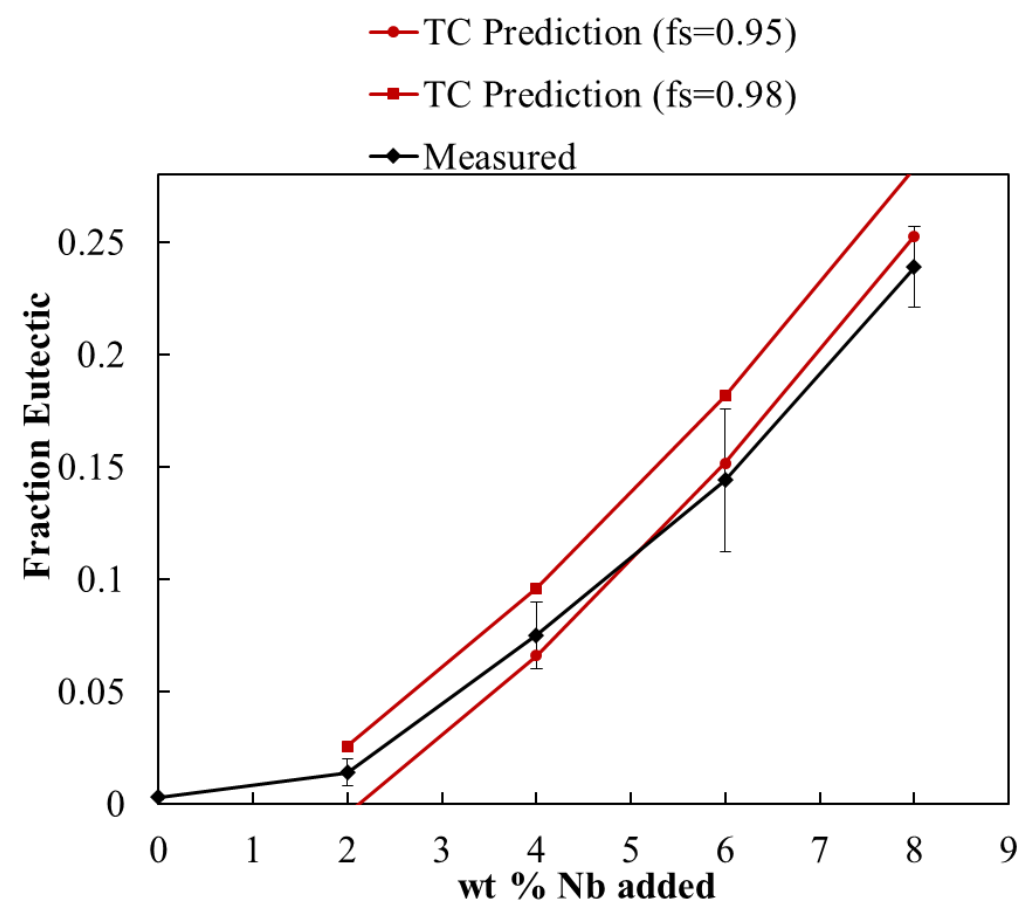

Figure 3. Thermocalc ${ }^{\mathrm{TM}}$ predictions of fraction eutectic at two different fraction solid levels in the simulation compared to measured values. Note that the lower fraction solid $\left(f_{S}=0.95\right)$ provides the best correlation to measured values. 


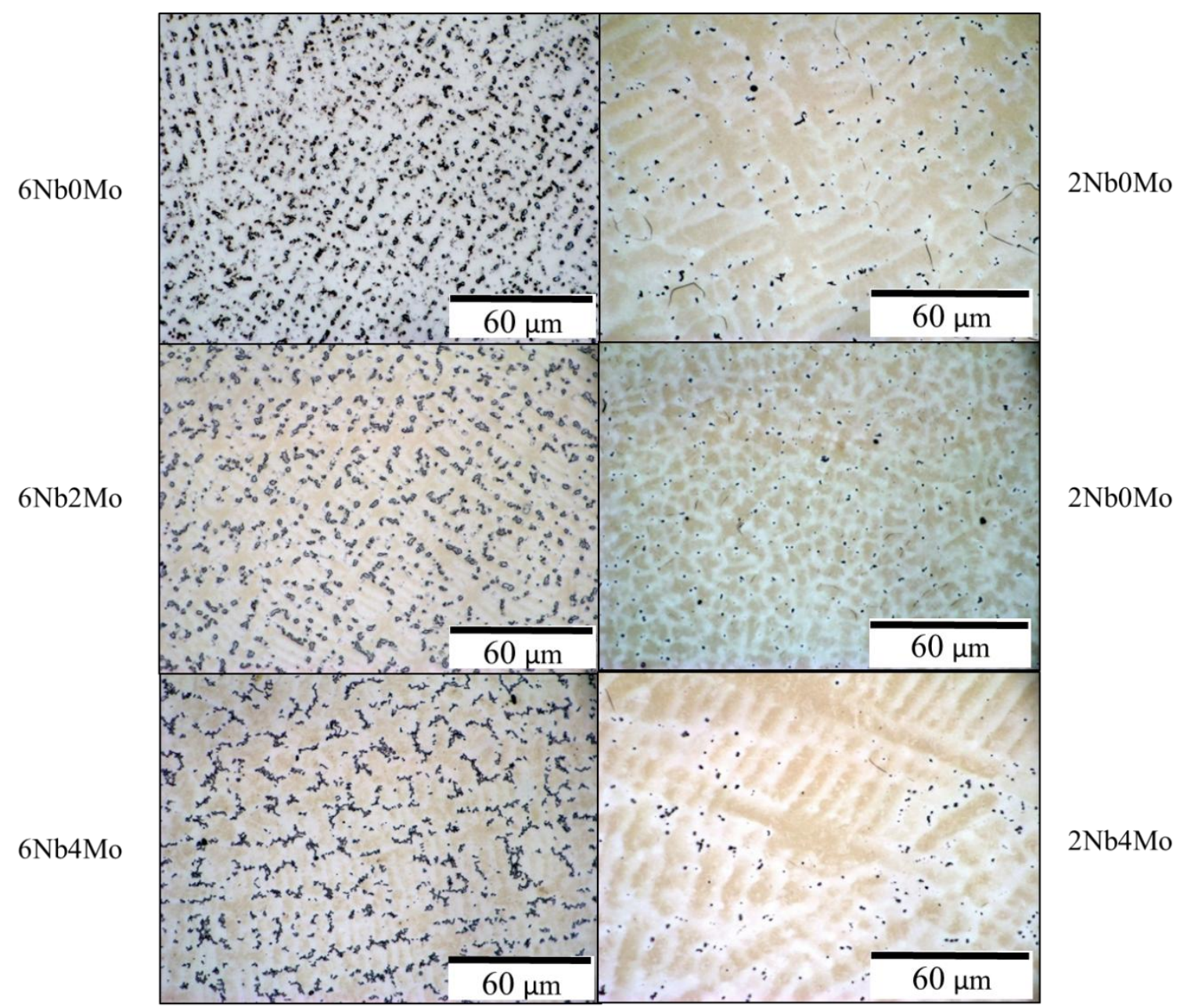

Figure 4. Optical micrographs comparing the Nb-rich eutectic with and without Mo additions. 


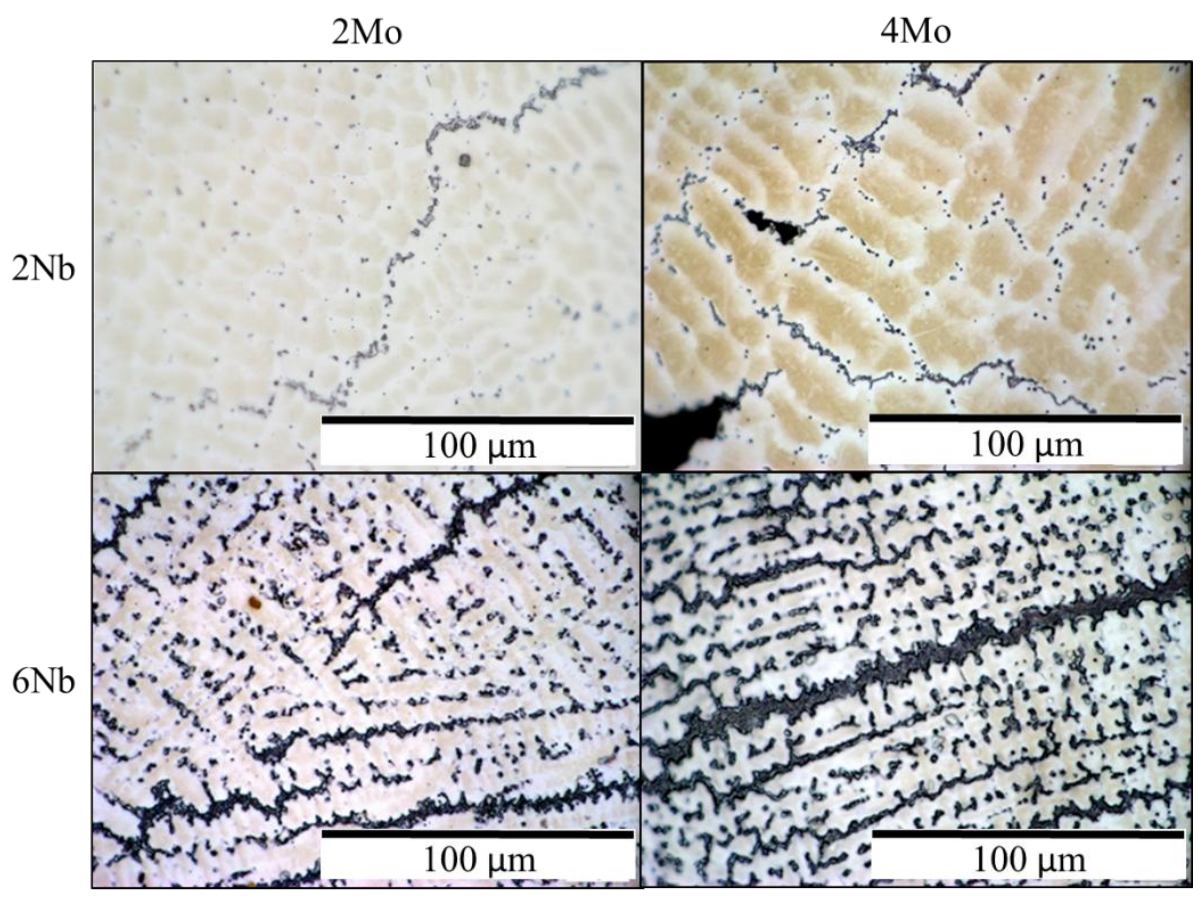

Figure 5. Backfilled cracks in samples containing both $\mathrm{Nb}$ and Mo. The backfilled cracks are the wide dark-etching regions that represent solidification grain boundaries in the weld metal.

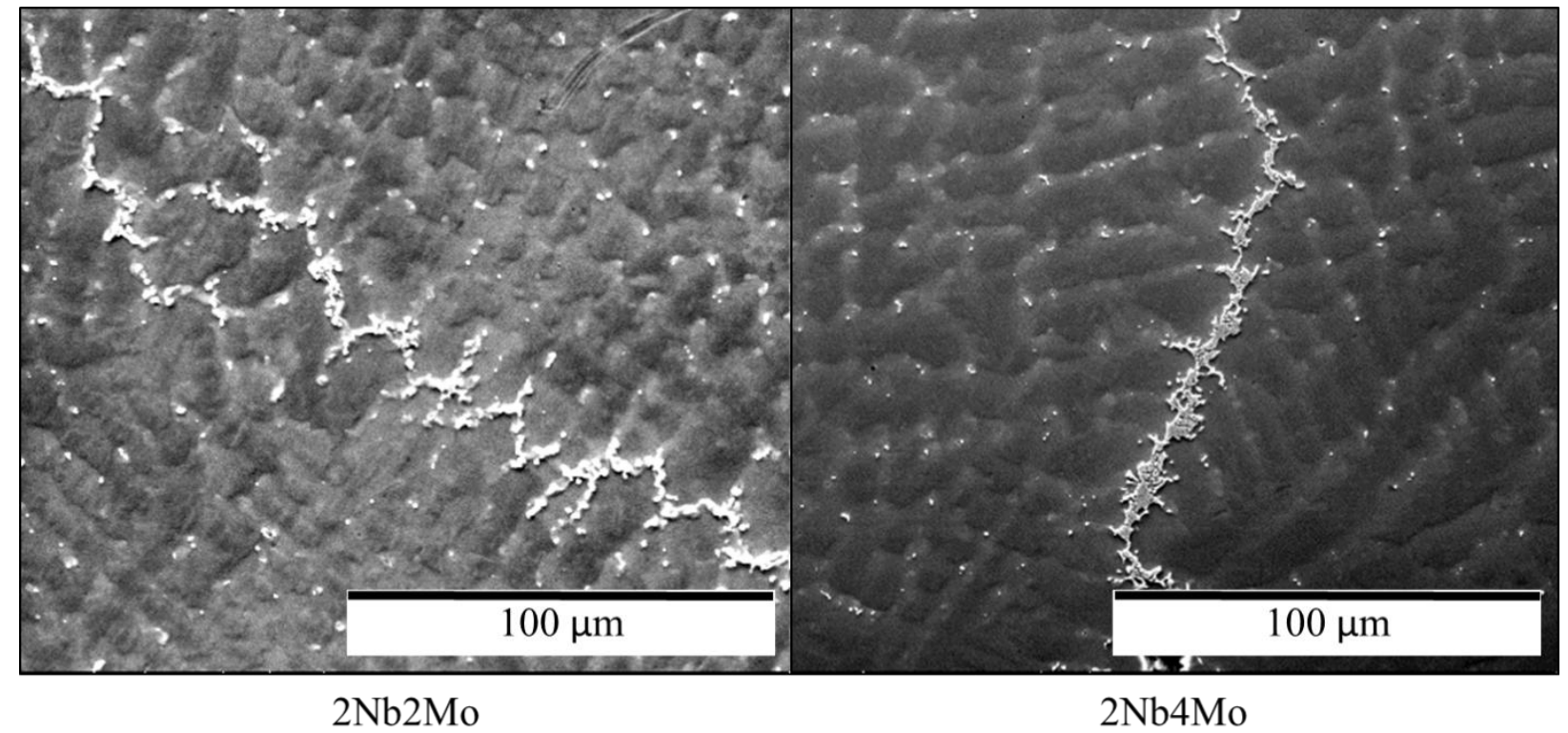

Figure 6. SEM micrographs of backfilled cracks for $2 \mathrm{Nb}$ alloys with Mo additions. 


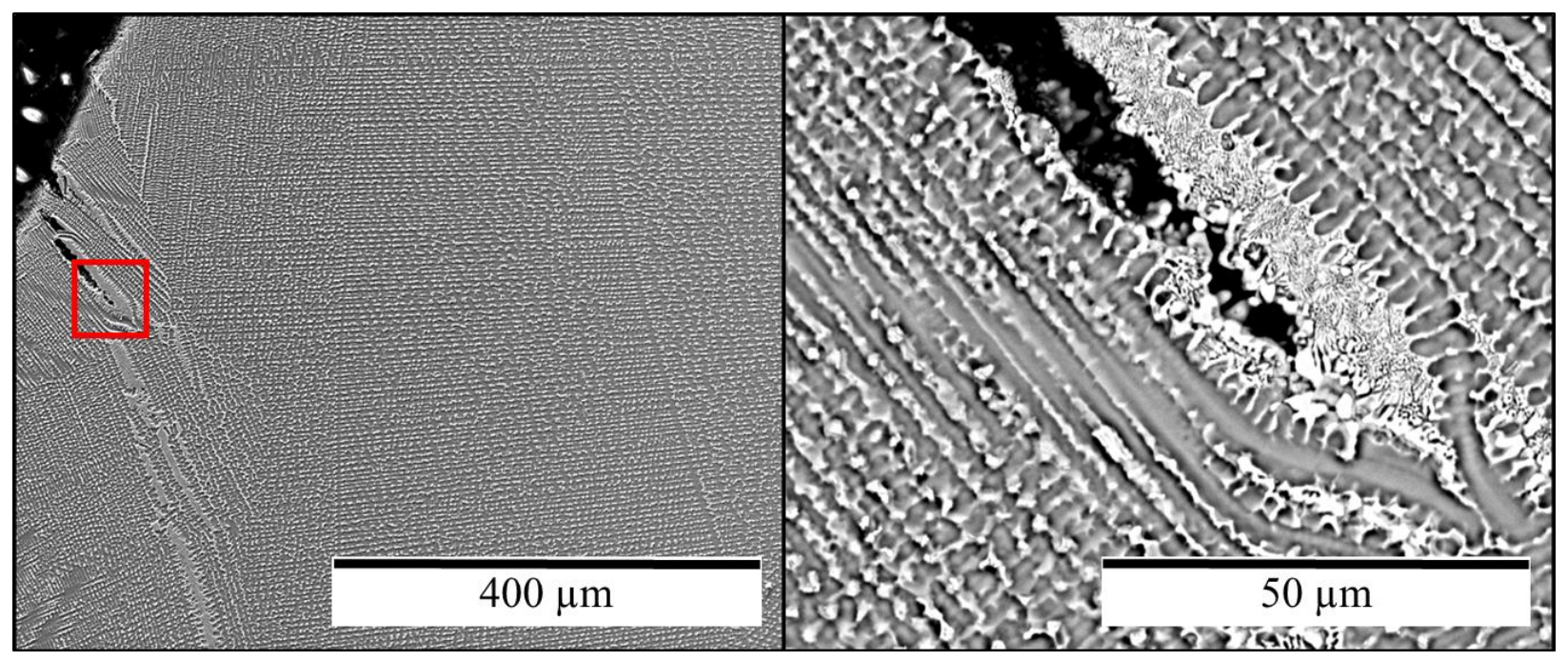

Figure 7. Backfilled cracks in an $8 \mathrm{Nb} 0 \mathrm{Mo}$ sample near the surface of the cast pin.

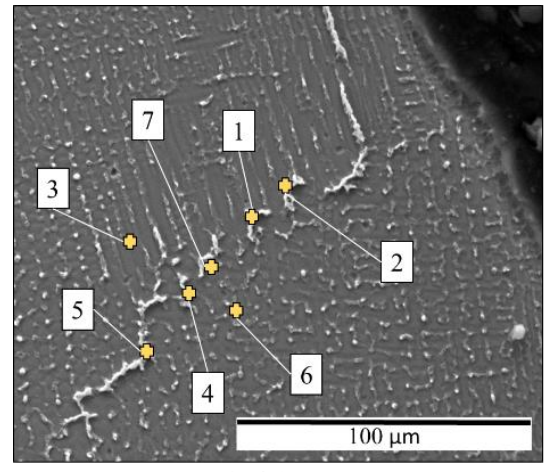

$4 \mathrm{Nb} 0 \mathrm{Mo}$

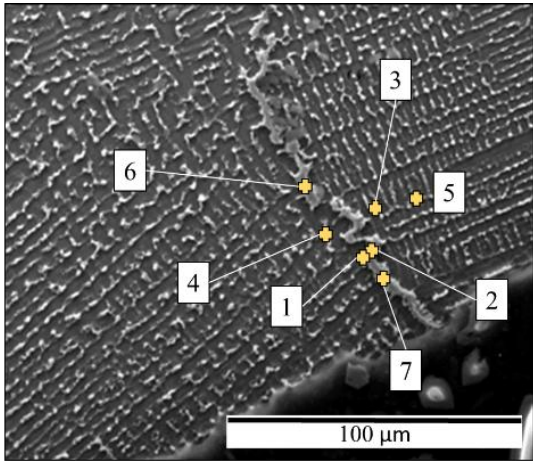

$6 \mathrm{Nb} 0 \mathrm{Mo}$

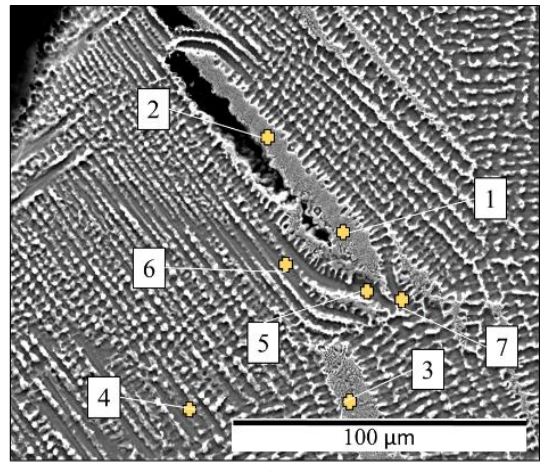

$8 \mathrm{Nb} 0 \mathrm{Mo}$

Measured Weight Percent

\begin{tabular}{|c|cc|c|c|c|c|c|c|}
\hline Composition & Element & Spot \#1 & Spot \#2 & Spot \#3 & Spot \#4 & Spot \#5 & Spot \#6 & Spot \#7 \\
\hline \multirow{2}{*}{$2 \mathrm{Nb} 2 \mathrm{Mo}$} & $\mathrm{Nb}$ & 1.86 & 1.62 & 15.38 & 15.5 & 14.52 & 0.92 & --- \\
\cline { 2 - 10 } & $\mathrm{Mo}$ & 1.65 & 1.63 & 3.15 & 3.99 & 3.89 & 1.43 & --- \\
\hline \multirow{2}{*}{$2 \mathrm{Nb} 4 \mathrm{Mo}$} & $\mathrm{Nb}$ & 2.31 & 15.57 & 2.31 & 16.01 & 15.27 & 2.34 & --- \\
\cline { 2 - 10 } & $\mathrm{Mo}$ & 3.81 & 8.21 & 3.81 & 8.23 & 8.61 & 3.56 & -- \\
\hline $4 \mathrm{Nb} 0 \mathrm{Mo}$ & $\mathrm{Nb}$ & 18.55 & 21.07 & 1.5 & 22.15 & 22.85 & 1.48 & 2.09 \\
\hline $6 \mathrm{Nb} 0 \mathrm{Mo}$ & $\mathrm{Nb}$ & 27.37 & 4.83 & 2.86 & 6.53 & 16.61 & 17.42 & 26.62 \\
\hline \multirow{2}{*}{$6 \mathrm{Nb} 2 \mathrm{Mo}$} & $\mathrm{Nb}$ & 2.08 & 3.29 & 22.81 & 21.14 & 2.21 & 20.2 & -- \\
\cline { 2 - 9 } & $\mathrm{Mo}$ & 1.33 & 1.54 & 3.59 & 3.15 & 1.47 & 2.93 & --- \\
\hline \multirow{2}{*}{$6 \mathrm{Nb} 4 \mathrm{Mo}$} & $\mathrm{Nb}$ & 20.88 & 21.42 & 2.06 & 2.29 & 4.02 & 21.3 & --- \\
\cline { 2 - 9 } & $\mathrm{Mo}$ & 6.75 & 7.49 & 2.81 & 2.89 & 3.48 & 7.09 & --- \\
\hline $8 \mathrm{Nb0Mo}$ & $\mathrm{Nb}$ & 24.52 & 23.67 & 24.83 & 4.21 & 3.34 & 3.42 & 3.27 \\
\hline
\end{tabular}


$2 \mathrm{Nb} 2 \mathrm{Mo}$
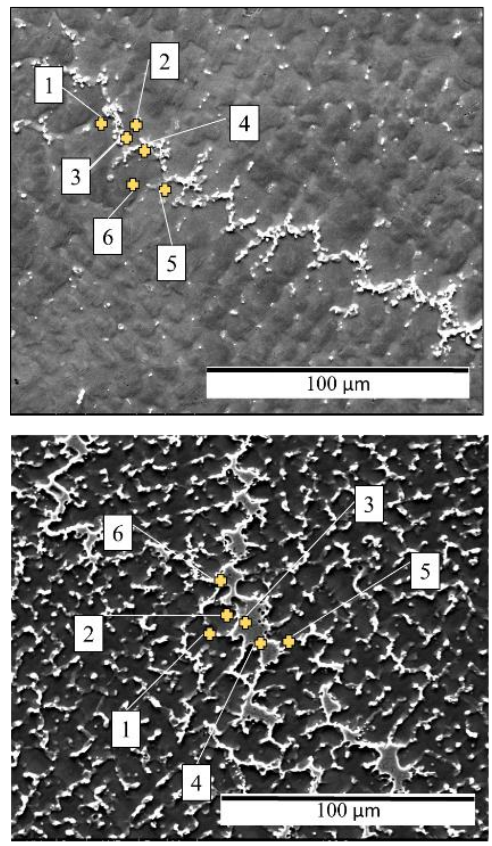

$6 \mathrm{Nb} 2 \mathrm{Mo}$
$2 \mathrm{Nb} 4 \mathrm{Mo}$
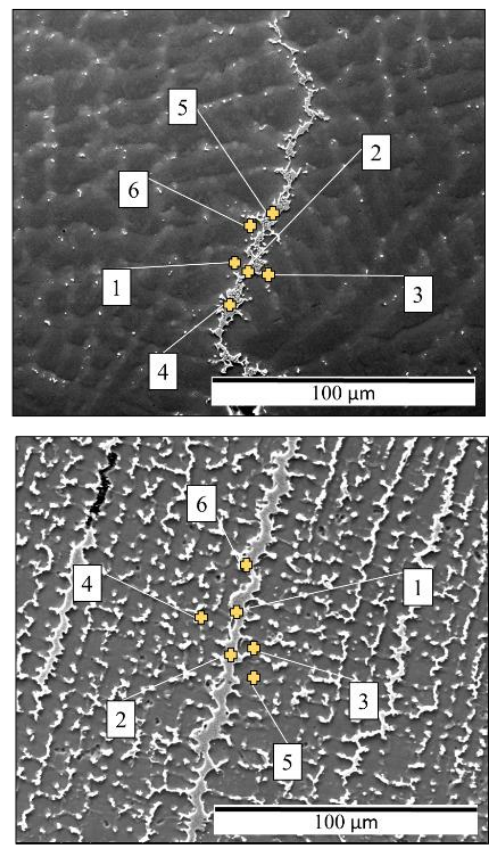

$6 \mathrm{Nb} 4 \mathrm{Mo}$

Figure 8. $\mathrm{Nb}$ and Mo wt. \%, determined via EDS at various locations in samples is depicted. 